\title{
Differential activity and clinical utility of latanoprost in glaucoma and ocular hypertension
}

This article was published in the following Dove Press journal:

Clinical Ophthalmology

2 June 2012

Number of times this article has been viewed

\author{
Fernanda Pacella \\ Paolo Turchetti \\ Valentina Santamaria \\ David Impallara \\ Gianpaolo Smaldone \\ Chiara Brillante \\ Aloisa Librando \\ Angela Damiano \\ Jose Pecori-Giraldi \\ Elena Pacella \\ Department of Sense Organs, \\ University of Rome "Sapienza", \\ Roma, Italy
}

Correspondence: Fernanda Pacella Department of Sense Organs, Viale del Policlinico, Rome 0016I, Italy

Tel +390649975305

$\mathrm{Fax}+390649975304$

Email pacella.ferny@libero.it
Background: The purpose of this study was to demonstrate the hypotensive efficacy and tolerability of latanoprost when used as monotherapy and as polytherapy associated with antiglaucomatous medication proven to be ineffective in keeping intraocular pressure under control.

Methods: Three hundred and thirty-seven patients ( 672 eyes) affected by primary open-angle glaucoma and intraocular hypertension were recruited over a period of 10 years from the Glaucoma Centre, Department of Ophthalmological Sciences, University of Rome "Sapienza", and treated, subject to informed consent, with latanoprost $0.005 \%$ alone or in combination with other ocular hypotensive drugs. The patients were followed during this period at regular intervals, with determination of visual field, fundus oculi, visual acuity, and eventual onset of local and systemic side effects.

Results: Latanoprost used as monotherapy and as polytherapy renders possible optimal and durable control of intraocular pressure in the form of one antiglaucomatous drug because it can substitute for one or more drugs and obtain the same hypotensive effect.

Conclusion: Latanoprost can be described as the ideal hypotensive drug, not only because of its ideal compliance profile (only one daily dose in the evening), excellent hypotensive effect, and, above all, few systemic side effects.

Keywords: latanoprost, glaucoma, ocular hypertension, intraocular pressure

\section{Introduction}

Analogs of prostaglandins (such as latanoprost, a prodrug of prostaglandin F2 $\alpha$ ) have been used as antiglaucomatous therapy since $1995 .{ }^{1}$ Prostaglandins are eicosanoids belonging to the family of autacoids, and constitute a group of molecules with ubiquitous distribution that performs various physiological functions in many organs and tissues, and vary according to type of prostaglandin and the receptor upon which it acts. For example, at the ocular level, prostaglandins induce miosis (albeit not in all animal species), vasomotor hyperemia, and disruption of the hemato-ophthalmic barrier, causing increased capillary protein permeability and increased intraocular pressure. While the action on EP2 receptors induces an increment in pressure at the ocular level, the opposite effect is obtained with the action of prostaglandin F $2 \alpha$ on the prostanoid FP receptor. Latanoprost is an inactive esterified prodrug of the isopropyl group that becomes biologically active following hydrolysis in the acid form. The prodrug, well absorbed through the cornea, is hydrolyzed and then activated during its passage across the aqueous humor.

From 1980 until the present day, several derivatives of prostaglandin F2 $\alpha$ have been tested, ${ }^{2-5}$ including prostaglandin F2 $\alpha$-isopropyl ester (IE), PHXA34 (13,14-dihydro-15 
(R,S)-17 fenil-18,19,20-trinor-prostaglandin-IE) epimeter of PHXA41 (13,14 dihydro, 15 (5), 17 fenil, 18, 19, 20 trinor prostaglandin F2 $\alpha$-IE), from which latanoprost (Xalatan ${ }^{\circledR}$ ) is derived and shown to have the widest clinical application. After various studies carried out in animals, human experiments were performed in order to evaluate the hypotensive effect in subjects with glaucoma. While prostaglandins E2 and D2 increased intraocular pressure, prostaglandin F2 (in the form of the tromethamine salt of prostaglandin F2 $\alpha$ applied locally), although having notable side effects, decreased intraocular pressure in the order of 3-4 $\mathrm{mmHg}$. These effects could be reduced by inserting into position 1 an external isopropyl which was more liposoluble (prostaglandin F2 $\alpha$-IE), thus allowing a smaller dose to be administered, which was activated by corneal esterase.

Prostaglandin F2 $\alpha$-IE is a potent ocular hypotensive agent with no effect on production of aqueous humor or on conventional outflow. Doses inferior to those on the dose-response curve are considered suitable for clinical use, whereas high doses produce numerous side effects, in part mitigated by reducing the use of the 1,15 diester.

A considerable reduction in intraocular pressure (by 25\%) and side effects ${ }^{1-3,6}$ is obtained by positioning a phenolic group (PhXA34) in position 17, obtaining a racemic product (PHXA41), resulting in an extremely effective R-epimer form, which at the same time permits dose reduction.

The mechanism of action by which latanoprost reduces intraocular pressure is based on facilitating uveoscleral outflow. Uveoscleral passage starts at the base of the iris and passes through the ciliary muscle in the over ciliary space and then into the superchoroidal space. ${ }^{7}$ The action of a prostaglandin on the ciliary muscle occurs in a manner related to the length of the stimulus. The first short-term effect that manifests itself is relaxation of the ciliary muscle induced by receptors specific for prostaglandins present in the muscle itself. In contrast, the long-term effect depends on readaptation induced in the extracellular matrix adjacent to the fibers of the ciliary muscle, with loss of connective tissue and subsequent facilitation of uveoscleral outflow through the muscle fibers.

Recent studies have clarified the distribution of the main prostaglandin receptors affecting intraocular pressure in the human eye, ie, prostaglandin E1, prostaglandin E2, and prostaglandin F2 $\alpha$. EP1 receptors have been identified in the ciliary body and the sphincter of the iris, EP3 receptors are found in the trabecular meshwork and ciliary muscle, and FP receptors (mainly acted upon by prostaglandins) are exclusively localized in the ciliary muscle. This latter phenomenon would explain the selective actions of prostaglandin F2 $\alpha$ and latanoprost on uveoscleral outflow. It is important to emphasize that the hypotensive effects of prostaglandin F $2 \alpha$ and latanoprost are due to the action of very low doses of these substances which act selectively on FP receptors. The aim of this study was to demonstrate the hypotensive activity and good tolerability of latanoprost, both as monotherapy and when used to replace antiglaucomatous medications which have proven to be ineffective in keeping intraocular pressure under control.

\section{Materials and methods Preliminary study}

Two groups of patients were recruited to participate in a randomized multicenter, double-blind study in which one group of patients received latanoprost $0.005 \%$ once a day and the other group received timolol $0.5 \%$ twice a day for 6 months. ${ }^{8}$ Seventy-one patients with primary open-angle glaucoma were selected. Their mean age was $63.3 \pm 10.5$ years, they comprised 35 females and 36 males. Both groups were then followed for a further 18 months with latanoprost administered as a single daily dose.

\section{Long-term study}

Over a period of 10 years, 266 patients affected by primary open-angle glaucoma and ocular hypertension were treated, having given their informed consent. Of these, 132 were males of average age $61.39 \pm 14$ years, and 134 were females of average age $64.20 \pm 13.55$ years, for a total of 530 eyes (two cases were monocular). During the first visit, all patients underwent the following examinations: biomicroscopy of the anterior segment; visual acuity; intraocular pressure; ocular fundus; manual and computerized perimetry; gonioscopy; and daily tonometric curve. When the diagnosis of primary open-angle glaucoma and ocular hypertension had been confirmed, treatment was initiated with latanoprost at a concentration of $0.005 \%$ in monotherapy or in association with other antiglaucomatous drugs.

At regular time intervals, intraocular pressure (every 2-3 months), perimetry (every 10-12 months) and annual examination of the ocular fundus and visual acuity were carried out, taking the eventual onset of local and systemic collateral effects into consideration. We excluded eyes that presented with anomalies in the corneal profile (eg, keratoconus) and alterations of the corneal epithelium (inflammatory and/or degenerative processes), and wearers of soft contact lenses. Patients were included in the study if they had had latanoprost substituted for one of their drugs, 


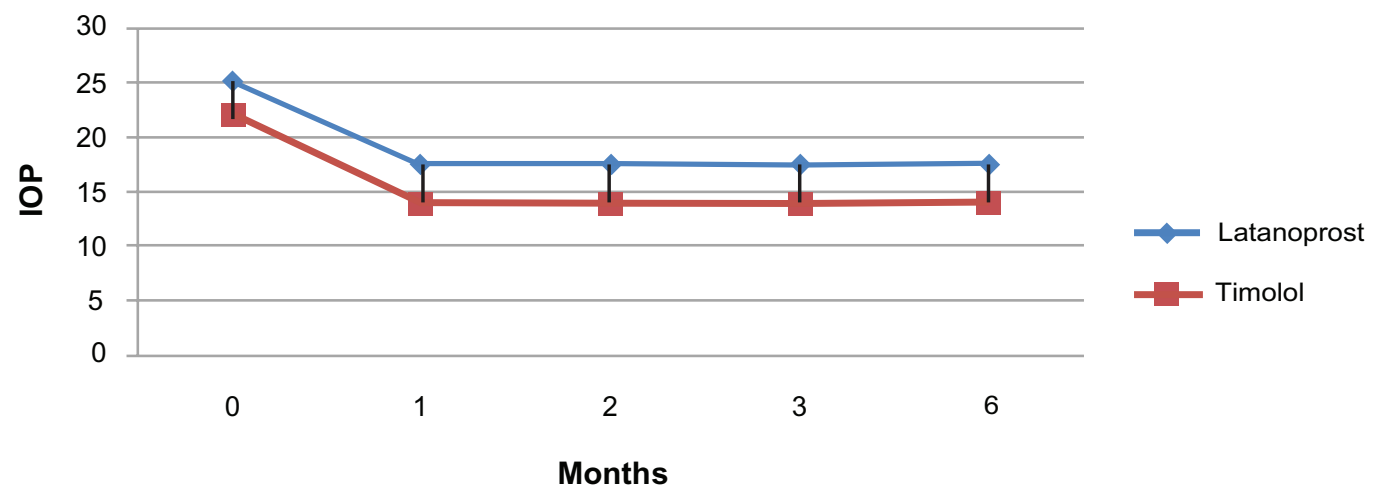

Figure I Mean intraocular pressure values before and after administration of latanoprost once daily and timolol $0.5 \%$ twice daily.

if latanoprost had been added to conventional therapy, and if dual therapy had been substituted by latanoprost as monotherapy. Statistical analysis was performed using the Student's $t$-test. $P=0.01$ was considered to be statistically significant.

\section{Results}

\section{Preliminary study}

It was demonstrated that latanoprost administered once daily and timolol $0.5 \%$ twice daily were able to significantly $(P<0.001)$ reduce mean intraocular pressure by a mean $8 \mathrm{mmHg}$. Figure 1 illustrates the mean course of intraocular pressure in both eyes at various time intervals (months 0,1 , $2,3,6$ ) following the administration of latanoprost once daily and timolol $0.5 \%$ twice daily. Of interest is that even after only one month of treatment with latanoprost, there was an average reduction of intraocular pressure of $23.15 \%$ which remained constant during the entire 12-month period of observation. Table 1 shows a statistical analysis of intraocular pressure values obtained before and 12 months after the start of latanoprost once daily.

\section{Long-term study}

Drugs which were substituted by latanoprost to achieve an increase in hypotensive activity are described in Table 2. It may be seen that the drugs more frequently substituted were parasympathomimetics (14.33\%), anhydrase inhibitors (10.94\%), and beta-blockers (8.67\%). Table 3 shows the association of latanoprost and other ocular hypotensive drugs with different mechanisms of action which proved ineffective in reducing intraocular pressure.

These studies demonstrate that latanoprost can be particularly useful in the medical treatment of some forms of glaucoma, such as normotensive glaucoma, where the damage cannot be specifically attributed to a steady increment in intraocular pressure. Other studies ${ }^{1,6,9,10}$ have demonstrated that latanoprost at concentrations of $0.005 \%$ administered once daily achieves an average intraocular pressure reduction of $35 \%$ in patients with primary open-angle glaucoma and ocular hypertension.

Given the fact that latanoprost increases uveoscleral outflow, it can be used as adjunctive therapy with other drugs having different hypotensive ocular activity, such as beta-blockers, carbonic anhydrase inhibitors administered both systemically and locally, alpha stimulants, and cholinergic drugs.

In order to demonstrate the effectiveness of latanoprost as monotherapy compared with maximum antiglaucomatous therapy that proved insufficient in keeping intraocular pressure under control in patients affected by primary open-angle glaucoma, we proceeded with evening administration in addition to a combination of antiglaucomatous drugs, the latter having demonstrated their ineffectiveness in keeping intraocular pressure under control. Assessments at months 1 , 2, 3, 6, and 9 following addition of latanoprost consistently showed a statistically significant $(P=0.001)$ reduction in intraocular pressure compared with baseline values.

During a decade of experience with latanoprost, we noted local collateral effects, consisting of dysepithelization $(1.13 \%)$, dryness of the periocular skin $(0.37 \%)$, ocular

Table I Statistical analysis of intraocular pressure values prior to and after latanoprost instillation

\begin{tabular}{|c|c|c|c|c|}
\hline \multirow{2}{*}{$\begin{array}{l}\text { Time } \\
\text { months }\end{array}$} & \multirow[t]{2}{*}{ Eyes (n) } & \multicolumn{2}{|c|}{ Intraocular pressure } & \multirow[t]{2}{*}{$P$} \\
\hline & & Median \pm MSE & $\boldsymbol{t}$ & \\
\hline 0 & 35 & $23.20 \pm 0.53$ & - & - \\
\hline 3 & 35 & $16.97 \pm 0.49$ & 8.631 & 0.001 \\
\hline 6 & 35 & $17.11 \pm 0.38$ & 9.338 & 0.001 \\
\hline 9 & 35 & $|7.7| \pm 0.43$ & 8.044 & 0.001 \\
\hline 12 & 35 & $17.89 \pm 0.45$ & 7.637 & 0.001 \\
\hline
\end{tabular}

Abbreviation: MSE, mean standard error. 
Table 2 Incidence of drugs more frequently substituted by latanoprost

\begin{tabular}{ll}
\hline Drugs & Incidence \\
\hline Parasympathomimetics & $14.33 \%$ \\
Carbonic anhydrase inhibitors & $10.94 \%$ \\
Beta-blockers & $8.67 \%$ \\
Alpha-mimetics & $6.41 \%$ \\
\hline
\end{tabular}

dryness $(0.70 \%)$, ocular pain $(1.13 \%)$, peripalpebral edema (3.52\%), and lacrimation (2.81\%). Evidence of cystoid macular edema, described by some authors, was very rare in our experience during treatment of aphakic or pseudoaphakic eyes. However, according to the literature, such manifestations cannot be confidently attributed to the drug because they have never been documented during clinical trials. Other topical side effects observed were: edema of the lacrimal caruncle $(0.70 \%)$, keratitis $(1.40 \%)$, growth of the cilium (7.04\%), and irideal hyperpigmentation $(2.81 \%$, the latter phenomenon starts concentrically at the pupil edge and does not recede after interruption of the therapy; this is due to stimulation by the drug of melanogenesis in the iris stroma $\left.^{3,5}\right)$. This is due to stimulation by the drug of melanogenesis in the iris stroma. ${ }^{3,5}$

The drug was well tolerated locally, with the exception of one eye in one patient who, after 3 months, developed a keratopathy comprising corneal disepithelization with parenchymal infiltration in the left eye, and treatment was suspended for this reason. However, when only one eye is involved, it is difficult to establish cause and effect due to latanoprost. Regarding systemic collateral effects associated with administration of latanoprost, the following were found: headache $(2.11 \%)$, vertigo $(1.40 \%)$, dry fauces $(0.70 \%)$, dermatitis $(0,70 \%)$, and gastroesophageal reflux $(0.18 \%)$. The latter receded as soon as latanoprost was interrupted, and then reappeared within one month of restarting the drug.

\section{Discussion}

Numerous antihypertensive pharmacological therapies can be used in patients affected by glaucoma and ocular

Table 3 Incidence of drugs more frequently associated with latanoprost

\begin{tabular}{ll}
\hline Drugs & Percentage \\
\hline Beta-blockers & $33.20 \%$ \\
Anhydrase inhibitors & $19.63 \%$ \\
Miotics & $1.88 \%$ \\
Alpha-mimetics & $3.01 \%$ \\
Combination of beta-blockers and anhydrase inhibitors & $19.61 \%$ \\
\hline
\end{tabular}

hypertension, and there is no single drug that can be considered to be the best choice for a given patient. The six classes of drugs (miotics, beta-blockers, alpha-agonists, adrenalin derivatives, carbonic anhydrase inhibitors, prostaglandin analogs) and their combinations offer more than 20 different medication options.

Pharmacokinetics of drugs administered locally involve interaction with the lacrimal film, intraocular factors, and corneal penetration; each of these steps can be influenced by the vehicle, $\mathrm{pH}$, from drug concentration, and the preservatives used. Upon penetration into the cornea, the drugs have to cross the aqueous humor to reach the structures on which they act in the anterior segment of the eye. Some of the drug is eliminated via diffusion into the vascular system or leakage with the aqueous humor across the outflow system, while the remainder is delivered to the various ocular tissues.

It appears that latanoprost is efficacious with a durable hypotensive effect when used as monotherapy and also demonstrates good pharmacological synergism when used in association with other drugs that have not demonstrated efficacy in keeping intraocular pressure under control. Moreover, latanoprost is effective when substituted for one or two drugs used in association, and manifests the same ocular hypotensive effect. Furthermore, latanoprost enables better compliance as a result of needing administration only once daily in the evening, compared with other antiglaucomatous drugs that usually require two or more administrations daily. 1,6 Finally, the drug is well tolerated in terms of the local and systemic side effects.

\section{Disclosure}

The authors report no conflicts of interest in this work.

\section{References}

1. Alm A, Stjernschantz J. Effects on intraocular pressure and side effects of $0.005 \%$ latanoprost applied once daily, evening or morning. A comparison with timolol. Scandinavian Latanoprost Study Group. Ophthalmology. 1995;102:1743-1752.

2. Alm A, Widengrand I, Kjllengren D, et al. Latanoprost administered once daily cause a maintained reduction of intraocular pressure in glaucoma patients treated concomitantly with timolol. Br J Ophthalmol. 1995;79: $12-16$.

3. Wistrand P, Stjernschantz J, Olsson K. The incidence and time-course of latanoprost induce iridial pigmentation as a function of eye colour. Surv Ophthalmol. 1997;41:S129-S138.

4. Camras CB, Bito LZ, Eakins KE. Reduction of intraocular pressure by prostaglandins applied topically to the eyes of conscious rabbits. Invest Ophthalmol Vis Sci. 1977;16:1125-1134.

5. Camras CA, Siebold EC, Lustgarten JS, et al. Maintained reduction of intraocular pressure by prostaglandin F2 alpha-1-isopropyl ester applied in multiple doses in ocular hypertensive and glaucoma patients. Ophthalmology. 1989;96:1329-1337. 
6. Camras CB. Comparison of latanoprost and timolol in patients with ocular hypertension and glaucoma. A six-month, masked, multicenter trial in the United States. The United States Latanoprost Study Group. Ophthalmology. 1996;103:138-147.

7. Bill A, Phillips CI. Uveoscleral drainage of aqueous humuor in human eyes. Exp Eye Res. 1971;12:275-281.

8. Pecori Giraldi J, Librando A, Simeone L. Our experience with latanoprost in open-angle glucoma. Boll Ocul. 2000;79:32.
9. Villumsen J, Alm A. The effect of adding prostaglandin F2 alphaisopropylester to timolol in patients with open angle glaucoma. Arch Ophthalmol. 1990;108:1102-1105.

10. Pacella E, Pacella F, Cavallotti C, Librando A, Feher J, Pecori-Girardi J. The combination latanoprost-timolol versus twice daily $0.50 \%$ timolol administration either associated or not with latanoprost: efficacy and tolerability of the primary open-angle glaucoma. Eur Rev Med Pharmacol Sci. 2010;14:477-480.
Clinical Ophthalmology

\section{Publish your work in this journal}

Clinical Ophthalmology is an international, peer-reviewed journal covering all subspecialties within ophthalmology. Key topics include: Optometry; Visual science; Pharmacology and drug therapy in eye diseases; Basic Sciences; Primary and Secondary eye care; Patient Safety and Quality of Care Improvements. This journal is indexed on

Submit your manuscript here: http://www.dovepress.com/clinical-ophthalmology-journal

\section{Dovepress}

PubMed Central and CAS, and is the official journal of The Society of Clinical Ophthalmology (SCO). The manuscript management system is completely online and includes a very quick and fair peer-review system, which is all easy to use. Visit http://www.dovepress.com/ testimonials.php to read real quotes from published authors. 